Beaumont, Alexander ORCID:

https://orcid.org/0000-0002-5773-6356, Forrest, Laura, Unnithan, Viswanath and Sculthorpe, Nicholas (2020) Cardiovascular Responses During Submaximal Cycling With and Without LeftLateral Tilting: Insights For Practical Applications of Stress Echocardiography. Applied Physiology, Nutrition, and Metabolism.

Downloaded from: http://ray.yorksj.ac.uk/id/eprint/4693/

The version presented here may differ from the published version or version of record. If you intend to cite from the work you are advised to consult the publisher's version: https://doi.org/10.1139/apnm-2020-0391

Research at York St John (RaY) is an institutional repository. It supports the principles of open access by making the research outputs of the University available in digital form. Copyright of the items stored in RaY reside with the authors and/or other copyright owners. Users may access full text items free of charge, and may download a copy for private study or non-commercial research. For further reuse terms, see licence terms governing individual outputs. Institutional Repository Policy Statement

\title{
RaY
}

Research at the University of York St John

For more information please contact RaY at ray@yorksj.ac.uk 


\section{Cardiovascular Responses During Submaximal Cycling With and Without Left-Lateral Tilting: Insights For Practical Applications of Stress Echocardiography}

Alexander J. Beaumont PhD*, Laura J. Forrest PhD, Viswanath Unnithan PhD, Nicholas Sculthorpe $\mathrm{PhD}$

\section{Affiliation at the time of study}

AJB, LJF, VU, NS: Institute of Clinical Exercise \& Health Sciences, School of Science and Sport, University of the West of Scotland, Stephenson Place, Hamilton International Technology Park Blantyre, Glasgow, UK

* Corresponding Author:

Dr Alexander J. Beaumont

School of Science, Technology and Health

York St. John University

York

United Kingdom

Email: a.beaumont1@yorksj.ac.uk

Contact information for other authors:

Laura J. Forrest: laura.forrest@uws.ac.uk

Viswanath Unnithan: vish.unnithan@uws.ac.uk

Nicholas Sculthorpe: nicholas.sculthorpe@uws.ac.uk

Current Affiliation that differs to the time of study

AJB: School of Science, Technology and Health, York St. John University, York, United Kingdom, UK 


\begin{abstract}
We investigated the cardiorespiratory responses to semi-supine exercise with $\left(\mathrm{SS}-45^{\circ}\right)$ and without $\left(\mathrm{SS}-0^{\circ}\right)$ a left-lateral tilt in fifteen adults, at fixed power output $(70 \mathrm{~W})$ and matched heart rates. At $70 \mathrm{~W}$, oxygen uptake and heart rate reduced from upright to SS- $0^{\circ}$ then increased to $\mathrm{SS}-45^{\circ}(\mathrm{p}<0.05)$. At matched heart rates, oxygen uptake and efficiency were lowest in SS$45^{\circ}(\mathrm{p}<0.05)$. Left-lateral tilting should not be performed under the assumption that each position replicates the same cardiorespiratory responses.
\end{abstract}

\title{
Novelty
}

- Cardiorespiratory responses to exercise are influenced by left-lateral tilting, which should not be performed under the assumption that physiological responses are replicated between left-lateral positions.

Keywords: exercise; stress echocardiography; left-lateral tilt; cardiovascular; cardiorespiratory; cycling 


\section{INTRODUCTION}

Purpose-built cycle ergometers for stress echocardiography utilise left-lateral tilting to facilitate image acquisition (Lancellotti et al. 2017). There is no specified degree of semisupine (SS) lateral tilt recommended (Lancellotti et al. 2017) but the degree of rotation varies to optimise image quality. Laboratory investigations have employed exercise protocols including upright (Unnithan et al. 2015) and (semi)supine positions, with the latter conducted using differing left-lateral tilt angles (Stöhr et al. 2012; Beaumont et al. 2017). The cardiometabolic responses during submaximal exercise between upright and SS/recumbent body positions have been studied (Saitoh et al. 2005; Egaña et al. 2013), yet the influences of left-lateral tilting are unknown.

Studies typically assess functional reserve using fixed power outputs (Unnithan et al. 2015) or power output relative to a predetermined maximum (Beaumont et al. 2017). However, this results in different heart rate (HR), metabolic and gas exchange profiles between individuals. Since many functional cardiac measures are known to be HR dependent, this makes inter-study comparisons challenging. To overcome this, studies can use a fixed target HR but this results in very different power outputs and oxygen uptake $\left(\mathrm{V}_{2}\right)$ between individuals for the same HR (Carrick-Ranson et al. 2014).

Investigations commonly ascertain maximal exercise performance using an upright cycling position, and then apply the required workload as a specific percentage in a (semi)supine position with a left-lateral tilt (Stöhr et al. 2012). Although maximal oxygen uptake is similar in upright and SS tilted positions, maximal workload is lower in the latter (Forton et al. 2016), and this uncoupling of oxygen uptake and power output is seldom considered, especially at submaximal workloads. 
Therefore, the aim of the present study was to investigate the cardiorespiratory responses during submaximal cycling in upright and SS positions with and without a left-lateral tilt during fixed power output and HR matched exercise.

\section{Materials and Methods}

\section{Participants}

Fifteen healthy and normally-active participants volunteered to participate ( 9 males and 6 females; age, $25 \pm 4$ years; stature, $175.8 \pm 7.5 \mathrm{~cm}$; body mass, $74.4 \pm 2.9 \mathrm{~kg}$; body mass index, $23.9 \pm 3.3 \mathrm{~kg} \cdot \mathrm{m}^{2}$ ). A medical questionnaire was used to determine and exclude any past or present knowledge of cardiovascular or cardiorespiratory diseases and diabetes. Before the experimental day, participants were asked to refrain from performing vigorous physical exercise (48 hours) and the consumption of caffeine or alcohol (24 hours). Participants provided written informed content before their participation in the study, which was reviewed and approved by the school ethics committee. All procedures were conducted in accordance with the Declaration of Helsinki.

\section{Experimental protocol}

Participants attended the laboratory twice at least 24 hours apart. The first visit was a familiarisation session whereby participants were acquainted with the cycle ergometer (ergoselect 1200P, ergoline GmbH, Germany) in the SS position without a left-lateral tilt (SS$\left.0^{\circ}\right)$ and with a left-lateral tilt to $45^{\circ}\left(\mathrm{SS}+45^{\circ}\right)$. The ergometer was adjusted to a vertical inclination angle of $23^{\circ}$ (the highest possible inclination to achieve left-lateral tilt) and the seat height, hip and arm supports were adjusted to their preferred position. Participants cycled at 70 watts and $70 \mathrm{rpm}$ for $5-\mathrm{min}$ at $\mathrm{SS}-0^{\circ}$ and $\mathrm{SS}+45^{\circ}$; separated by 5 -min passive recovery. The second visit was the main experimental day and following 5-min rest in each of the 3 positions 
(upright, $\mathrm{SS}-0^{\circ}$ and $\mathrm{SS}+45^{\circ}$ ), participants performed 5 x 5-min bouts of submaximal cycling at $70 \mathrm{rpm}$, separated by 5 min passive recovery. This study employed semi-randomisation with participants first completing upright ergometry (Monark, 874E, Sweden) at 70W, followed by 4x5 min bouts of submaximal cycling on the SS ergometer in a randomised order. Two matched power output $(70 \mathrm{~W})$ bouts were performed at $\mathrm{SS}-0^{\circ}$ and $\mathrm{SS}+45^{\circ}$, in addition to two matched $\mathrm{HR}$ bouts (HR matched to upright cycling) at $\mathrm{SS}-0^{\circ}$ and $\mathrm{SS}+45^{\circ}$. See Supplementary Material S1 for illustration of SS- $0^{\circ}$ and $\mathrm{SS}+45^{\circ}$.

Blood pressure (ergoline, Germany) and HR (H7, Polar Electro, Finland) were recorded within the last 2 min for each exercise bout. Power output (W) was noted for bouts 4 and 5 (matched HR) at the termination of cycling. Rate pressure product (RPP) was the product of HR and SBP, which represented myocardial demand (Armstrong et al. 2016). Oxygen pulse $\left(\mathrm{O}_{2}\right.$ pulse) was determined as $\dot{\mathrm{VO}}_{2} / \mathrm{HR}$. The breath-by-breath metabolic system (MetaMax 3B, Cortex, Germany) was calibrated for gas and flow, with a smoothing of 3 moving data points applied during analysis, for the determination of $\dot{\mathrm{V}} \mathrm{O}_{2}$, carbon dioxide $\left(\mathrm{V}_{\mathrm{CO}}\right)$ and minute ventilation $\left(\dot{\mathrm{V}}_{\mathrm{E}}\right)$. These indices were recorded as the average of the final minute for all conditions. Gross efficiency (GE) was calculated (Gaesser and Brooks 1975) following the determination of the rate of energy expenditure (EE) (Brouwer 1957). The difference between resting and exercise EE were used to determine the true energy cost (TEC), which in turn was used in the calculation of NE (Gaesser and Brooks 1975). See Supplementary Material S2 for detailed equations. RPE (Borg 1970) and rating of perceived comfort [(RPC] modified according to Borg et al., (1970)) were recorded. For bouts 4 and 5, measurements were not collected until HR was within \pm 5 beats. $\min ^{-1}$ of the target HR. 


\section{Statistical analysis}

Statistical analyses were performed using SPSS (V.23 and V.25; IBM Company, SPSS Inc., Chicago, USA). Data normality was assessed by Shapiro-Wilk. The effect of tilt position was compared within matched power output and matched HR, separately. For normally distributed data, one-way repeated measures analysis of variance (ANOVA), followed by Bonferroni post hoc. For non-normally distributed data, a Friedman test was used followed by the Wilcoxen signed-rank test for post hoc analyses, with manual Bonferroni correction applied to the statistical significance alpha level for multiple pairwise comparisons. Statistical significance was granted as $\mathrm{p} \leq 0.05$.

\section{Results}

Cardiorespiratory variables during exercise for fixed power output and HR matched conditions are shown in Table 1.

\section{Fixed power output}

$\mathrm{HR}$ was lower in $\mathrm{SS}-0^{\circ}$ than upright and $\mathrm{SS}+45^{\circ}$, yet greater in $\mathrm{SS}+45^{\circ}$ compared with upright $(\mathrm{p}<0.05)$. RPP, $\dot{\mathrm{V}} \mathrm{O}_{2}$ and $\dot{\mathrm{V}} \mathrm{CO}_{2}$ were lower in $\mathrm{SS}-0^{\circ}$ compared with upright and $\mathrm{SS}+45^{\circ}(\mathrm{p}<0.05)$, which did not differ between upright and $\mathrm{SS}+45^{\circ} \cdot \dot{\mathrm{V}}_{\mathrm{E}}$ was lower in $\mathrm{SS}-0^{\circ}$ compared to upright and $\mathrm{SS}+45^{\circ}$, however, $\dot{\mathrm{V}}_{\mathrm{E}}$ was greater in $\mathrm{SS}+45^{\circ}$ than upright (all $\mathrm{p}<0.05$ ). $\mathrm{EE}$ and TEC were lower in SS- $0^{\circ}$ than upright and $\mathrm{SS}+45^{\circ}(\mathrm{p}<0.05)$. GE and NE were greater in SS $-0^{\circ}$ than upright and $\mathrm{SS}+45^{\circ}(\mathrm{p}<0.05)$, with no differences in EE, TEC, GE or NE between upright and $\mathrm{SS}+45^{\circ}(\mathrm{p}>0.05)$. RPE and RPC were greater in $\mathrm{SS}+45^{\circ}$ compared with upright and SS-0 $0^{\circ}(\mathrm{p}<0.05)$. 


\section{Matched HR}

Power output was greater in SS- $0^{\circ}$ compared to upright and $\mathrm{SS}+45^{\circ}$, but was lower in upright than $\mathrm{SS}+45^{\circ}(\mathrm{p}<0.05) . \dot{\mathrm{V}} \mathrm{O}_{2}$ was similar between upright and $\mathrm{SS}-0^{\circ}(\mathrm{p}>0.05)$ but lower in $\mathrm{SS}+45^{\circ}$ than upright and $\mathrm{SS}-0^{\circ}(\mathrm{p}<0.05) . \dot{\mathrm{V}} \mathrm{CO}_{2}$ was lower in $\mathrm{SS}+45^{\circ}$ than upright $(\mathrm{p}<0.05)$, yet comparable to $\mathrm{SS}-0^{\circ}(\mathrm{p}>0.05) . \mathrm{O}_{2}$ pulse did not differ between upright and $\mathrm{SS}-0^{\circ}(\mathrm{p}>0.05)$, yet was lower in $\mathrm{SS}+45^{\circ}$ than $\mathrm{SS}-0^{\circ}(\mathrm{p}<0.05)$. EE was lower in $\mathrm{SS}+45^{\circ}$ than upright $(\mathrm{p}<0.05)$ but similar to $\mathrm{SS}-0^{\circ}(\mathrm{p}>0.05)$. TEC, GE and NE were lower in $\mathrm{SS}+45^{\circ}$ than upright and $\mathrm{SS}-0^{\circ}$ $(p<0.05)$. Whereas, GE and NE were greater in SS- $0^{\circ}$ than upright $(p<0.05)$. RPE and RPC were greater in $\mathrm{SS}-0^{\circ}$ and $\mathrm{SS}+45^{\circ}$ than upright, while $\mathrm{RPC}$ was greater in $\mathrm{SS}+45^{\circ}$ than $\mathrm{SS}-0^{\circ}$ $($ all $\mathrm{p}<0.05)$.

\section{Discussion}

This study identified that left-lateral tilting during SS exercise at matched power output reduces cycling efficiency and removes the cardiovascular advantages of SS cycling without a lateral tilt, compared to upright exercise. Secondly, despite similar HR and RPP during matched HR exercise, power output and mechanical efficiency were variable between positions.

At matched power output, submaximal ergometry was more efficient in the SS-0 position compared with upright, whereby metabolic state $\left(\dot{\mathrm{V}} \mathrm{O}_{2}, \dot{\mathrm{V}} \mathrm{CO}_{2}, \dot{\mathrm{V}}_{\mathrm{E}}, \mathrm{RER}\right)$ and myocardial work (HR, RPP) reduced, while cycling efficiencies (GE and NE) increased. As a comparison with the same external power output $(70 \mathrm{~W})$, our observations conflict with other work that has observed no difference in $\mathrm{HR}, \mathrm{RPP}$ and $\dot{\mathrm{VO}}_{2}$ between upright and recumbent cycling $\left(70^{\circ}\right)$ (Saitoh et al. 2005). The authors speculated an insufficient venous return to induce physiological differences between positions, whereas the lower incline angle $\left(\sim 23^{\circ}\right)$ used in this study could hold some accountability for reduced myocardial work and superior 
efficiency during low-moderate intensity exercise. Moreover, the back support during ergometery in SS- $0^{\circ}$ could have contributed to enhanced cycling efficiency with localisation of muscular work to the lower extremities, in contrast to the additions of upper extremity and trunk activation with upright cycling (Saitoh et al. 2005).

Our study provides novel documentation that the cardiovascular advantages were lost when exercising with a left-lateral tilt. Accordingly, it is reasonable to suggest that for a given absolute workload (W), the degree of left-lateral tilt should be standardised to minimise the variation in cardiovascular response during submaximal exercise. We utilised $\mathrm{SS}-0^{\circ}$ and $\mathrm{SS}+45^{\circ}$ set points to gain insights pertaining to the maximum possible difference between position. Yet, the degree of tilt utilised in stress echocardiography is often the consequence of image quality and will likely vary between these set points, with some individuals requiring little-no tilt and others considerably more. Nevertheless, there is a clear trade-off between altering lateral tilt angle to optimise image acquisition, yet at the possibility of changeable myocardial work. Furthermore, body support in most cardiac imaging ergometers when in the $\mathrm{SS}+45^{\circ}$ position, is predominantly limited to underarm and hip anchor points. Handle bar gripping may be similar between upright and $\mathrm{SS}-0^{\circ}$ positions, while grasping the hand grip and blood pressure cradle for additional stabilisation in the $\mathrm{SS}+45^{\circ}$ posture compared to $\mathrm{SS}-0^{\circ}$, could have contributed to the elevated cardiovascular response. SBP increased to a greater extent from rest to exercise in $\mathrm{SS}+45^{\circ}(\Delta 45 \pm 12 \mathrm{mmHg})$ than $\mathrm{SS}-0^{\circ}(\Delta 33 \pm 8 \mathrm{mmHg}$; post-hoc, $\mathrm{p}<0.01$ ), which suggests some sustained isometric work. Greater RPE and RPC in $\mathrm{SS}+45^{\circ}$ may indicate a psychophysiological interaction from exercising in a relatively unfamiliar body position, along with a significant tilt angle that could have amplified the sympathetic response and magnified myocardial work beyond the physiological demand for physical exercise alone. We extend prior work of lower maximal workload in $\mathrm{SS}+33^{\circ}$ (using a similar ergometer as in this study) than upright (Forton et al. 2016), by reporting that a given submaximal power output 
did not elicit the same physiological response in upright and SS positions. Therefore, it may not be feasible to apply a percentage of maximal workload obtained in the upright position to a SS position for submaximal exercise and consequently, it may be more advisable to conduct maximal and submaximal exercise tests in the same position.

When exercise is prescribed using low intensity HR matching, comparable RPP suggests similar myocardial demand between upright, $\mathrm{SS}-0^{\circ}$ and $\mathrm{SS}+45^{\circ}$ positions. The lower power output in $\mathrm{SS}+45^{\circ}$ was not matched by a reduction in HR, SBP or RPP. Despite reduced power output, which may also provide an explanation for the lower $\mathrm{EE}$ and $\mathrm{O}_{2}$ pulse in the $\mathrm{SS}+45^{\circ}$ position compared to upright and $\mathrm{SS}-0^{\circ}$ positions, respectively, this posture was still associated with the lowest NE and GE. The reduction in power output is likely responsible for the decrease in $\dot{\mathrm{VO}}_{2}$ and consequently, there appears an uncoupling between myocardial work and whole-body metabolic state during submaximal exercise. Some individuals may be more influenced by the body position (tilt) than the intensity of exercise per se, such that HR becomes elevated above the metabolic demands of the exercise intensity. This is supported by the lower TEC of exercise in the $\mathrm{SS}+45^{\circ}$ cycling position which implies that less muscular work was required to elicit the same $\mathrm{HR}$ in $\mathrm{SS}+45^{\circ}$ position. This means cardiac observations may be performed at a target HR with the patient performing less physical work without changes in perception of exertion, and may be advantageous in populations with limited exercise tolerance. The present observations may enable clinicians and researchers to adjust left-lateral tilt angle, since myocardial work was similar with or without tilting. However, this is at the consequence of a reduced cycling efficiency, power output and $\mathrm{VO}_{2}$ in the $\mathrm{SS}+45^{\circ}$ position and thus, for a given $\mathrm{HR}$ during exercise in the $\mathrm{SS}+45^{\circ}$ position, may not be predictive of the metabolic demands and TEC of SS- $0^{\circ}$ or normal, upright ergometry. Although, it has been suggested that the variabilities in systemic $\dot{\mathrm{V}}_{2}$ and cardiac function could be related (Armstrong et al. 2016). Thus, despite exercising at a fixed HR, increasing the lateral tilt angle 
may as a result, influence markers of cardiac function, yet this requires further exploration with cardiac imaging.

Only young, healthy individuals were included in this study which limits the inference to other populations. Clinical groups may require a greater positioning challenge and within these individuals, image quality would likely take precedence. Although attempts were made to maintain $\mathrm{HR}$ in the target range, $\mathrm{HR}$ response was variable in some individuals during the $\mathrm{SS}+45^{\circ}$ position despite a considerable lowering of power output. Therefore, the ability to control HR in the left-lateral position may be compromised in some individuals. We randomised the SS positions while upright exercise was performed first which may impart some ordering bias. This ordering sequence was necessary to ascertain the target HR for subsequent SS cycling bouts. To build upon the present exploratory investigation, future studies are warranted to investigate the influence of left-lateral tilting on clinically relevant markers of cardiac function derived from imaging.

In conclusion, this study demonstrated that left-lateral tilting during SS, matched power output (W) exercise reduces cycling efficiency and removes the cardiorespiratory advantages of SS cycling observed in the SS-0 position compared with upright exercise. Whereas, matched HR exercise was not coupled with power output of metabolic demand. Therefore, irrespective of the chosen method to elicit an exercise intensity, left-lateral tilting should not be performed under the assumption that each position replicates the associations between HR, power, cardiovascular and metabolic responses to a physiological exercise stress.

\section{Author contributions}

All authors report no conflicts of interest. 


\section{References}

Armstrong, C., Samuel, J., Yarlett, A., Cooper, S.-M., Stembridge, M., and Stöhr, E.J. 2016. The Effects of Exercise Intensity vs. Metabolic State on the Variability and Magnitude of Left Ventricular Twist Mechanics during Exercise. PLoS One 11(4). doi:10.1371/journal.pone.0154065.

Beaumont, A., Hough, J., Sculthorpe, N., and Richards, J. 2017. Left ventricular twist mechanics during incremental cycling and knee extension exercise in healthy men. Eur. J. Appl. Physiol. 117(1): 139-150. doi:10.1007/s00421-016-3506-8.

Borg, G. 1970. Perceived exertion as an indicator of somatic stress. Scand J Rehabil Med 2(2): 92-98.

Brouwer, E. 1957. On simple formulae for calculating the heat expenditure and the quantities of carbohydrate and fat oxidized in metabolism of men and animals, from gaseous exchange (Oxygen intake and carbonic acid output) and urine-N. Acta Physiol Pharmacol Neerl 6: 795-802.

Carrick-Ranson, G., Hastings, J.L., Bhella, P.S., Fujimoto, N., Shibata, S., Palmer, M.D., Boyd, K., Livingston, S., Dijk, E., and Levine, B.D. 2014. The effect of lifelong exercise dose on cardiovascular function during exercise. J. Appl. Physiol. 116(7): 736-745. doi:10.1152/japplphysiol.00342.2013.

Egaña, M., Columb, D., and O’Donnell, S. 2013. Effect of low recumbent angle on cycling performance, fatigue, and $\mathrm{V}^{`} \mathrm{O}(2)$ kinetics. Med Sci Sports Exerc 45(4): 663-673. doi:10.1249/MSS.0b013e318279a9f2.

Forton, K., Motoji, Y., Deboeck, G., Faoro, V., and Naeije, R. 2016. Effects of body position on exercise capacity and pulmonary vascular pressure-flow relationships. J. Appl. Physiol. 121(5): 1145-1150. doi:10.1152/japplphysiol.00372.2016.

Gaesser, G.A., and Brooks, G.A. 1975. Muscular efficiency during steady-rate exercise: effects of speed and work rate. J Appl Physiol 38(6): 1132-1139. doi:10.1152/jappl.1975.38.6.1132.

Lancellotti, P., Pellikka, P.A., Budts, W., Chaudhry, F.A., Donal, E., Dulgheru, R., Edvardsen, T., Garbi, M., Ha, J.W., Kane, G.C., Kreeger, J., Mertens, L., Pibarot, P., Picano, E., Ryan, T., Tsutsui, J.M., and Varga, A. 2017. The Clinical Use of Stress Echocardiography in Non-Ischaemic Heart Disease: Recommendations from the European Association of Cardiovascular Imaging and the American Society of 
Echocardiography. J Am Soc Echocardiogr 30(2): 101-138.

doi:10.1016/j.echo.2016.10.016.

Saitoh, M., Matsunaga, A., Kamiya, K., Ogura, M.N., Sakamoto, J., Yonezawa, R., Kasahara, Y., Watanabe, H., and Masuda, T. 2005. Comparison of Cardiovascular Responses Between Upright and Recumbent Cycle Ergometers in Healthy Young Volunteers Performing Low-Intensity Exercise: Assessment of Reliability of the Oxygen Uptake Calculated by Using the ACSM Metabolic Equation. Archives of Physical Medicine and Rehabilitation 86(5): 1024-1029. doi:10.1016/j.apmr.2004.09.030.

Stöhr, E.J., McDonnell, B., Thompson, J., Stone, K., Bull, T., Houston, R., Cockcroft, J., and Shave, R. 2012. Left ventricular mechanics in humans with high aerobic fitness: adaptation independent of structural remodelling, arterial haemodynamics and heart rate. J Physiol 590(Pt 9): 2107-2119. doi:10.1113/jphysiol.2012.227850.

Unnithan, V.B., Rowland, T., Lindley, M.R., Roche, D.M., Garrard, M., and Barker, P. 2015. Cardiac strain during upright cycle ergometry in adolescent males. Echocardiography 32(4): 638-643. doi:10.1111/echo.12708. 
Table 1. Exercising cardiorespiratory responses in the upright and SS positions during matched power output and heart rate matched conditions.

\begin{tabular}{|c|c|c|c|c|c|c|}
\hline \multirow[b]{2}{*}{ Measure } & \multicolumn{3}{|c|}{ Matched power output } & \multicolumn{3}{|c|}{ Heart rate matched } \\
\hline & Upright & $\mathrm{SS}-0^{\circ}$ & $\mathrm{SS}+45^{\circ}$ & Upright & SS- $0^{\circ}$ & $\mathrm{SS}+45^{\circ}$ \\
\hline Power output (W) & $70 \pm 0$ & $70 \pm 0$ & $70 \pm 0$ & $70 \pm 0$ & $81 \pm 14 \dagger$ & $44 \pm 24 \dagger \dagger$ \\
\hline \multicolumn{7}{|c|}{ Cardiorespiratory parameters and efficiencies } \\
\hline HR (beats $\min ^{-1}$ ) & $119 \pm 17$ & $114 \pm 20 \dagger$ & $129 \pm 20 \dagger \dagger$ & $119 \pm 17$ & $118 \pm 18$ & $121 \pm 16$ \\
\hline $\mathrm{SBP}(\mathrm{mmHg})^{\mathrm{a}}$ & $145 \pm 13$ & $140 \pm 12$ & $145 \pm 14$ & $143 \pm 15$ & $148 \pm 14$ & $139 \pm 15$ \\
\hline $\mathrm{DBP}(\mathrm{mmHg})^{\mathrm{a}}$ & $73(13)$ & $69(11)$ & $70(20)$ & $72(12)$ & $69(10)$ & $72(18)$ \\
\hline RPP & $18319(6047)$ & $15271(4577) \dagger$ & $18748(5084) \ddagger$ & $17250(5986)$ & $17056(4191)$ & $16100(2956)$ \\
\hline \multicolumn{7}{|l|}{$\left(\text { beats.min }{ }^{-1} \cdot \mathrm{mmHg}\right)^{\mathrm{a}}$} \\
\hline $\mathrm{O}_{2}$ pulse $\left(\mathrm{mL} \cdot\right.$ beat $\left.^{-1}\right)$ & $10.9 \pm 1.9$ & $10.5 \pm 2.3$ & $10.7 \pm 2.3$ & $10.9 \pm 1.9$ & $11.0 \pm 2.3$ & $9.7 \pm 2.0 \ddagger$ \\
\hline$\dot{\mathrm{V}} \mathrm{O}_{2}\left(\mathrm{~mL} \cdot \mathrm{kg} \cdot \mathrm{min}^{-1}\right)$ & $18.0(4.8)$ & $15.0(3.7) \dagger$ & $18.1(4.0) \ddagger$ & $17.5 \pm 2.5$ & $17.2 \pm 2.6$ & $15.8 \pm 2.9 \dagger+$ \\
\hline$\dot{\mathrm{V} C O}{ }_{2}\left(\mathrm{~L} \cdot \mathrm{min}^{-1}\right)$ & $1.23 \pm 0.08$ & $1.04 \pm 0.08 \dagger$ & $1.29 \pm 0.17 \ddagger$ & $1.23 \pm 0.08$ & $1.16 \pm 0.14$ & $1.09 \pm 0.16 \dagger$ \\
\hline$\dot{\mathrm{V}}_{\mathrm{E}}\left(\mathrm{L} \cdot \mathrm{min}^{-1}\right)$ & $34.5 \pm 3.1$ & $30.0 \pm 3.2 \dagger$ & $38.2 \pm 4.5 \dagger \dagger$ & $34.5 \pm 3.1$ & $32.7 \pm 3.1$ & $32.8 \pm 4.1$ \\
\hline $\mathrm{EE}\left(\mathrm{J} \mathrm{s}^{-1}\right)$ & $445.8 \pm 24.6$ & $397.4 \pm 24.8 \dagger$ & $468.3 \pm 50.1 \ddagger$ & $445.8 \pm 24.6$ & $436.0 \pm 53.1$ & $402.7 \pm 60.9 \dagger$ \\
\hline Total Energy Cost $\left(\mathrm{J} \mathrm{s}^{-1}\right)$ & $331.1(32.2)$ & $300.7(28.9) \dagger$ & $360.2(63.0) \ddagger$ & $331.1(32.2)$ & $335.0(71.5)$ & $296.6(95.8) \dagger+$ \\
\hline $\mathrm{GE}(\%)$ & $15.7 \pm 0.8$ & $17.7 \pm 1.1 \dagger$ & $15.1 \pm 1.7 \ddagger$ & $15.7 \pm 0.8$ & $18.5 \pm 1.6 \dagger$ & $10.6 \pm 5.7 \dagger t$ \\
\hline
\end{tabular}


Ratings of perception

RPE

$11(4)$

$11(3)$

$14(4) \dagger \dagger$

$11(4)$

$12(2) \dagger$

$13(2) \dagger$

RPC

$10 \pm 2$

$11 \pm 2$

$16 \pm 2 \dagger \dagger$

$10 \pm 2$

$11 \pm 2 \dagger$

$16 \pm 1 \dagger+$

Data are presented as mean \pm standard deviation for normally distributed data or median (interquartile range) for non-normally distributed data.

${ }^{\text {a }} n=14$ for matched power output - variable HR. $S S+45^{\circ}$ semi-supine with a left-lateral tilt of $45^{\circ}, S S-0^{\circ}$ semi-supine without a left-lateral tilt, $S B P$ systolic blood pressure, $R P P$ rate pressure product, $R P E$ rating of perceived exertion, $R P C$ rating of perceived comfort, $\mathrm{O}_{2}$ pulse oxygen pulse, $N E$ net economy, $H R$ heart rate, $G E$ gross economy, $E E$ energy expenditure, $D B P$ diastolic blood pressure, $\dot{V}_{E}$ minute ventilation, $\dot{V} O_{2}$ volume of oxygen uptake, $\dot{\mathrm{V} C \mathrm{O}_{2}}$ volume of carbon dioxide production, $\uparrow \mathrm{p}<0.05$ compared to upright, $\ddagger \mathrm{p}<0.05$ compared to SS- $0^{\circ}$. 